\title{
The Effectiveness of Sustainable Development of the Saving for Production Groups in Northeast of Thailand
}

\author{
Nat Luxchaigul \\ Dept. of Humanities and Social Sciences, Prince of Songkla University, Pattani Campus \\ 181 Chareonpradit Road, Rusamilae, Muang, Pattani 94000, Thailand \\ Tel: 66-73-31-3930-50 \# 3063 E-mail: nat-1@ bunga.pn.psu.ac.th
}

Received: January 28, 2014

Accepted: February 11, 2014

doi:10.5296/emsd.v3i1.5182

URL: http://dx.doi.org/10.5296/emsd.v3i1.5182

\begin{abstract}
This paper has the objective to describe the effectiveness of sustainable development has been significant to get the advantage of competitiveness and growth in the country's economic, society and politics. The Saving for Production Groups (SPGs) in Northeast of Thailand had the significant role in developing the potential and capacity of people in local communities. Field trip survey was conducted for finding secondary data through concerning printed material. Primary data were obtained from in-depth interviewing of 4 saving groups and the samplings are leaders, members and stakeholders in Chaiyaphum, Kalasin, Nakhon Ratchasima and Ubon Ratchathani, this issue related in sustainable human capital development of SPGs.

The Result showed that SPGs manage the group regulations more than learning activities for developing capabilities of the committees and members; but member have been able to provide security for members and lesser public activities. The management principles were significant to the success of saving groups, effected by the leaders experiences which composited the sustainable economy principles, the guidelines on management of the Community Development Department and the management principles according to situations. The learning provision, local wisdoms had been used for knowledge creation of their own saving groups, which could be considered as developing capabilities of man or human capital in communities at the same time. The effectiveness of learning promotion of members, via the social economy activities, aimed at the unofficial learning which should provide the economic activities content in conformity with the needs and sustainable economy was of life. The learning promotions, via persons for increasing human and social capital were done by using the local media effectively, and learning from the outside of communities.
\end{abstract}

Keywords: Effectiveness of Sustainable Development, Human Capital, Learning Provision, 


\section{Macrothink \\ Environmental Management and Sustainable Development \\ ISSN 2164-7682 \\ 2014, Vol. 3, No. 1}

Saving for Production Groups (SPGs), Northeast of Thailand

\section{Introduction}

The ultimate goal of sustainable development is to improve the quality of life for all members of a community and, indeed, for all citizens of a nation and the world - while ensuring the integrity of the life support systems upon which all life, human and non-human, depends.

There is sometimes confusion about the meanings of "sustainable development" and "sustainability" and the relationship between them. A report on Education for Sustainable Development in New Zealand proposed the following explanation: Sustainability is the goal of sustainable development - an unending quest to improve the quality of peoples'lives and surroundings, and to prosper without destroying the life-supporting systems on which current and future generations of humans depend. Like other important concepts, such as equity and justice, sustainability can be thought of as both a destination and a journey. (Parliamentary Commissioner for the Environment, 2004)

The special contribution of the concept of sustainable development is that it emphasizes respect for cultural values and, thus, does not see economic indicators as the sole measure of development. Rather, sustainable development represents the balanced integration of social and environmental objectives with economic development. These three aspects of sustainable development - society, environment and economics - were named as the three pillars of sustainable development at the World Summit on Sustainable Development in Johannesburg in 2002. (UNESCO, 2010)

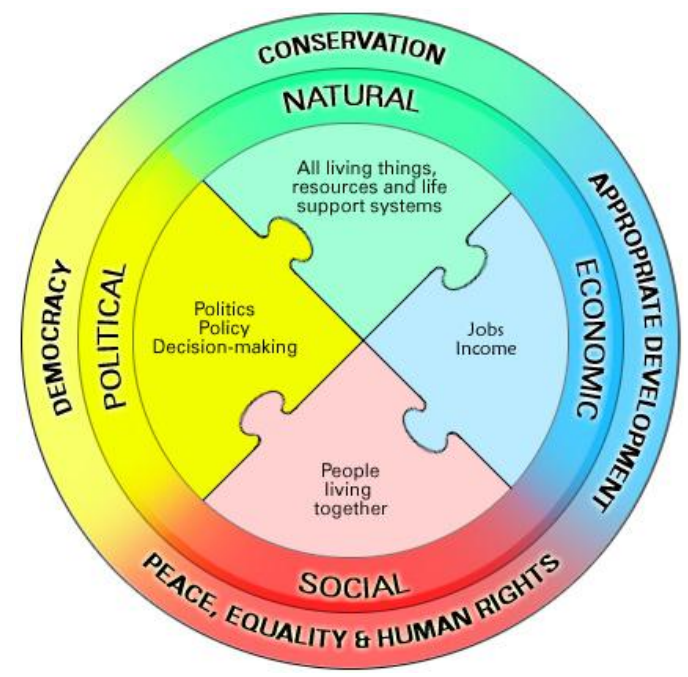

Figure 1. Four dimensions of sustainable development

As Shown in figure 1, a socially sustainable system must achieve distributional equity, adequate provision of social services including health and education, gender equity, and political accountability and participation. Next, an environmentally sustainable system must maintain a stable resource base, avoiding over-exploitation of renewable resource system or environment sink function, and depleting non-renewable resource only to the extent that 
investment is made in adequate substitutes. This includes maintenance of biodiversity, atmospheric stability, and other ecosystem functions not ordinarily classed as economic resources. Finally, an economically sustainable system must be able to produce goods and services on a continuing basis, to maintain manageable levels of government and external debt, and to avoid extreme sectorial imbalances with damage agricultural or industrial production. (Holmberg, 1992).

However, Politics, Natural and Culture are also a key dimension of sustainable development, which influence the interactions of and between the three pillars. They are concerned with the values we cherish, the ways in which we perceive our relationship with others and with the natural world, and with how we make decisions. As a result of the close relationships between the four these dimensions of sustainable development, achieving this goal requires a dynamic balance between: Production and consumption; Ecology and economics; Development and conservation; Culture and ecology; and Democracy and economics. (UNESCO, 2010).

In the past, Thailand has aimed at development the creative economy, industry and technology. There was revealed that can result in serious and life, social and natural. The country is experiencing economic crisis and the problem of inequality in the quality of life dramatically. Then began to develop a new concept is developed by the human at the center and seized in the National Economic and Social Development Plan, $8^{\text {th }}$ issue. (1997-2001), and adapted the sufficiency economy to the lifestyle which initiated by His Majesty King Blumibol.

Dhammapidok (2006) mentioned an important remorse as the aspect of the past which to make changes in the new development. Thailand country aimed to creating economic prosperity by more focusing on the role of science and technology. This adverse effected to life, society, natural and environment that lead to destruction. Then human - centered development not only life together, but also access to nature and be able to take the knowledge of the truth of nature to social system replacement. Finally, the goal is human coexistence in harmony with nature and most benefit.

Kongkasawat (2007) as the idea, related to human in the modern time, which views people as being the significant assets and having value for all organizations. However, the characteristics, different from other assets, are "Intangible Assets". It is because each person has knowledge, skills or expertise, capabilities, experiences and attributes which are difficult to be seen and touched. Therefore, there are no depreciation in value as other assets when have been used for a period of time. In the opposite direction, the added value always increases more and more from experiences, skills and knowledge of the person.

Of all above, the human-entered development should start at human potential first as learning by doing, which is an important feature to look for knowledge. In the part of organization dimension, Build up the business and organizational competitive advantages as studying the provision in human capital. Therefore, it is to create the added value to the organization especially the Economic Community Based Organizations (ECBOs) in rural area of the country where needs to be self-reliant in building up the economic society. Because of the 


\section{Macrothink}

Environmental Management and Sustainable Development

ISSN 2164-7682 2014, Vol. 3, No. 1

failures of the present government offices in development administering the local community by considering from the quality of life, happiness of people in community and the strengthened of self-reliance in the economic society, etc. According to the implementation model of these ECBOs are neither aimed at the capital collection nor built up the highest profit, but there are the target in order to develop the sustainable human capital within the community.

Grouping and working together in the community is the core of human sustainable development as saying: "No groups, No development" Therefore, the grouping studies are needed for understanding the efficient group management and the goal success or group productivities. In the meaning explanation of groups in community development, most scholars refer to the characteristics of people gathering in community where there are similar problems or needs, when goal of grouping and working together are set up as the problem-solving in their community. (PuangNgaam, 2010).

\section{The Saving for Production Groups Background}

Group or community organization, established in order to develop human capital, called Saving for Production Groups (SPGs) are the local people who regularly save money in their cash pool. This pool of money is used to invest in their economic activities. The collected profit can provide securities to the community members. SPGs are the functional roles which lead to the cooperation between the government sector and community in order to solve the problem of no cash investment, illegal loans, knowledge in producing and marketing as an occupation, etc.

As mentioned, SPGs' goals and implementation processes for developing the sustainable human capital of local community. It can say that the idea of the SPGs is combined with the Agricultural Cooperative, Cooperative Credit Union and Loan for Agriculture; gathering people, who are different economic status in village, help each other to solve their investment problems. Moreover, the community markets are not only the place for selling their products but also the marketing demonstration center. SPGs' activities are going to promote the learning process of local people for developing the individual, family and community by teaching person to help himself and others in the economic society, thrifty and saving. (Insawaang, 2000; Tangmelap \& Nuanlaor, 2001; Chotechuang, 2001; Bureau of Community Capital and Financial Organization Development, 2010) 


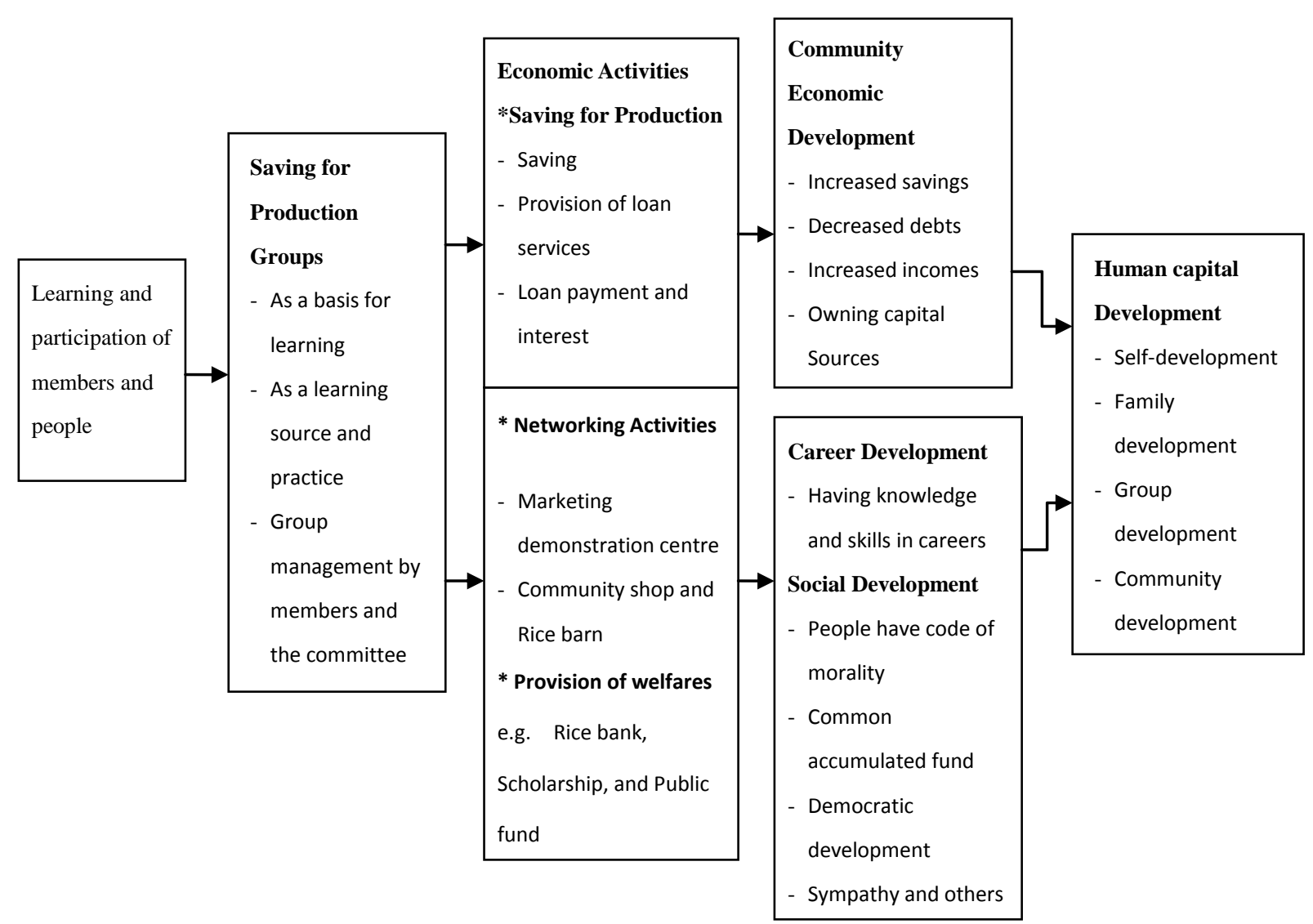

Figure 2. The SPGs Development Concept

As shown in Figure 2, the SPGs Development Concept helps increase human capital by the promotion of learning and member participation in group management and operation of economic activities. It can be concluded that SPGs is an important accumulation capital of human capital style in community. It aims to carry out the tasks for human development to be beyond poverty. This, places the importance on 5 aspects of virtue in the management are: honesty, sacrifice, responsibility, sympathy, and trustworthiness. Therefore, the management by the committee must be accountability and can be checked anytime.

\subsection{The Saving for Production Groups of Thailand}

According to the assessment of SPGs development throughout the country are 35,891 groups in 2009, it was found that 3,582 groups needed to be improved and 9,602 groups was found at a satisfactory level. (9.98 \& $26.75 \%$, respectively). (Bureau of Community Capital and Financial Organization Development, 2010). It has a tendency that SPGs will continually decrease in accordance with an idea of Richard L. Daft (1998) after passing the development period. Based on figure 2, the economic activities operation of SPGs begins with saving for the provision of welfares and loans to members to invest their business. Mostly, the activities focus on saving for production and it is the best way for fund accumulation. This is because it can help solve problems in quality of life based on socio-economic factor. 
As a whole, it is found that most SPGs admit trusted saving deposit and provide loans most $(94.1 \%)$. It has career promotion activities and provision of welfare: marketing demonstration center, rice bank, and rice barn (6.5, 3.4, and 1.5\%, respectively). (Luxchaigul, 2013). This truly reflects potential and benefits to be obtained from the economic activities of SPGs.

\subsection{The Saving for Production Groups in Northeast Thailand}

SPGs in Northeast area have 20 provinces accounts for the highest in number 17,744 groups or $50.11 \%$ of the country. (Luxchaigul, 2013). The groups are formed aiming at carrying out activities for community development in which human are the center in accordance with the National Social and Economic Development Plan, $8^{\text {th }}$ issue $(1997-2001)$. It placed the importance on the philosophy of sufficiency economy initiated by His Majesty King Blumibol. This was consistent with livelihoods and folk wisdoms which resulted in increased effectiveness on human capital development as follows:

\subsubsection{The Saving for Production Group of Baan Kham, Moo 2, Chiyaphum Province}

Baan Kham community is predominant in leadership with experience in community development; particularly on successful integration of various funds existing in the community. This is under the management by SPGs and common benefits, e.g. quality of life, socioeconomic security, and environment. Interestingly, the philosophy of sufficiency economy is adopted for the development activities, resulting in decreased expenses, increased incomes, and decreased debts. One member is allowed to get a loan with only one contract and he must grow a tree and take care of it.

The economic activities have an effect on human capital. That is, the group places the importance on benefits of its members. Public relations were done through word-of-mouth, village broadcast tower, and personnel media (community leaders and committee). Also, planners who are skillful in business are produced for development activities, e.g. problem solving on the purchase of agricultural yields, marketing negotiation, etc. This is on the basis of honesty, fair benefit sharing, and using part of profits for the purchase of materials, equipment, and farm machinery. Not only this, there is the establishment of the following: marketing demonstration center, community rice bank, rice barn, and other infrastructures, e.g. community water work, water source for agricultural purposes, and common rice field purchase for local people who do not have their own farm land. Aside from the extension of business opportunity welfares on birth, elderly, and mortality are provided at a sub-district level and its vicinity up to district and provincial levels.

\subsubsection{The Saving for Production Group of Baan Jod, Moo 16, Kalasin Province}

Baan Jod community is also predominant in leadership. Local people of various ages join group management and they are respectful to the elderly as well as the difference in opinions. They do not place the importance on financial aspect but group rules and regulations. Group leaders have operational guidelines for integrating various funds and groups in their community. This is because they have perceived an opportunity in problem solving on debts and the strengthening of the saving group and community. 
One advantageous aspect is that there is a diversity of community organizations, e.g. rice noodles community enterprise group, cloth weaving group, women saving group, sewing group, bio-fermented fertilizer group, etc. All of these reflect quality of human capital of the community. Besides, educational tours were held throughout the year.

2.2.3 The Saving for Production Group of Baan Thabsawai, Moo 1, Nakhon Ratchasima Province

Baan Thabsawai is a big community located near Nakhon Ratchasima city. It is progressive in infrastructures and convenience facility. However, this community has a problem in local politics which has an effect on the group management committee in terms of collaboration on community development among the village, career group, and SPGs. Due to non-continuity operation of the community organization and various career groups in the community; it is found that aside from activities of the marketing demonstration centre, SPGs, community financial management institute, housewife Mad-Mee silk weaving group, and community rice bank, there are careen groups and various communities which have been abolished. Some activities are carried out during growing and harvesting seasons, e.g. dessert cooking group, local music group, youth group, and rice farmers group. All of these have an effect on interest and community participation because these organization lack of leaders who lack of sacrifice and attention on development activities.

\subsubsection{The Saving for Production Group of Baan Nonghin, Moo 5, Ubon Ratchathani Province}

Baan Nonghin is a community not too far from Ubon Ratchathani city. It is predominant on leadership having knowledge and potential well accepted by people in the community. It can be observed that the saving group there is in the step of the adjustment of effective management. Representatives of various career groups take part in SPGs operation for potential development and promotion of career group operation. Since most careen groups and community organizations there are not strong and cannot be self-reliant, group leaders have an idea to develop it and they try to rehabilitate abolished activities and hold career training based on skills and interest of each individual.

It can be concluded that the management for increased effectiveness of human capital development arises from community leaders having vision and sacrifice. Besides, they are good planner who places the importance on common benefit. Although they are supported on materials and equipment by the Provincial Community Development Office, but when local people place the importance and participate in saving, activities on career development and welfares can be done continually. At the initial stage, the committee and members can learn together through community venue holding. This creates close relationships, unity and learning process until local people have confidence and apply for member status up to the present.

\subsection{Human Capital Development of Saving for Production Groups}

Developing human capital of SPGs is based on the nature of lifelong learning for effecting self-development through actual practice. This includes problems arising in daily life activities or livelihoods. Existing development activities of SPGs aims to be responsive to 
needs of local people which must be consistent with production plan of the community. It is therefore the driving force for mutual learning dynamic of people in the community. This process is happened again and again which helps elevate intellect level of group members. Outcomes of this learning process can help local people solve problems for the development of quality of live and intellectual capital. (Walaisathira, 2005)

\subsubsection{Group Leaders and Construction of Community Participation}

SPGs leaders are facilitators of community participation in social and economic activities. This participation is not depending on initiation and planning by the government sector but the success arises from community participation focusing on group work, i.e. perception, decision-making, coordination, planning, responsibility, monitoring, and benefit sharing. The components making saving group participation be effective are: coordination of group members on group and community development; capital mobilization of local people having different economic status; brain storming among group members; principle of self-reliance.

SPGs leaders having predominant characteristics on change leading are honest and they attempt to develop their community. Besides, they place the importance on common benefits and seeking for strength for self-reliance as well as strength and weakness points. This makes SPGs in Northeast of Thailand be strong and self-reliant. It can be a model for effective management which can be seen from the establishment of the learning center, saving groups, and being a source of educational tour of various saving groups and government agencies.

2.3.2 Operation on Activities of Self-reliance Networks and Enhancing Social and Economic Strength

Saving activities are initial activities of SPGs. It is the basis for developing and extending other development activities. In fact, SPGs has operational cost and be able to share profits to its members and province welfares to members and community. Regarding a number of activities on career promotion and successful business of saving group, most PSGs have the marketing demonstration center most (39.7\%). This is followed by rice barn $(25.3 \%)$, fertilizer selling (18.6\%), community shop (14.3\%) and rice mill $(12.4 \%)$ respectively. The following activities are found a little operation: drinking water factory (1.6\%), yield drying court (5.2\%) and gasoline station (7.8\%). (Luxchaigul, 2013).

There is an increase in cremation welfares and marking demonstration center but rice barn and rice bank are decreased. There is a tendency that the saving group places the importance on the provision of welfares for increased quality of life of group members. It is found that marking demonstration center is successful and get highest benefits most even though it needs a highest operational cost. Besides, there is a decrease in a number of rice banks because most local people there can grow rice for sale and house hold consumption more than ever.

\subsubsection{Learning Promotion for an Increase in the Effectiveness of Economic Activities}

SPGs have learning for an increase in the effectiveness of economic activities (at a moderate level). Thus, they have readiness and needs for increased learning experience. Regarding a 
guideline for an increase in the effectiveness of economic activities, it should place the importance on yields and learning outcomes on unity, obligation, activity participation, etc.

For problems encountered in learning of SPGs, it mostly arise for lack of learning process of the committee, e.g. training on management skills, accounting system, continual learning process facilitation within the group like public venue holding, meeting and group discussion.

\subsubsection{Saving Groups Development Strategies for Production of Supporting Agencies}

Supporting agencies and concerned personnel should focus on man center for development more than ever. Besides, the importance of group potential development should be emphasized based on continual knowledge exchange.

\subsection{Prior Research}

Most of review of related literature concern with human capital development through the operation of community organizations on career development and women roles on social and economic aspects. It is found that there is concern about the system of family and economy in Northeast Thailand most. This is because the people there have the lowest GNP in the country. More than one-half of the people there earn incomes form the agricultural sector. (Therasatwat, 2003) Besides, the topography condition in Northeast Thailand has an effect on livelihoods of the people stay in arid plateau. (SomIn, 1982). Therefore, the quality of life development of the people there needs coordination of government and private sectors by establishing a group or community organization for self-reliance. This aims to develop human capital by using finance as a tool for development in order to be self-reliant. However, there are problems in lack of knowledge in management and group activities participation. Thus, all group members must determine goals and rules or regulations of the groups.

It can be concluded that there are internal and external factors affecting the success of saving groups. That is, group members and the committee must follow rules and regulations of the group as well as participation and knowledge exchange (internal factors). Also, it should have support by both government and private sectors based on budgets, personnel, equipment, production factors, technology, information technology, etc. (external factors).

Based on review of related literature abroad, it is mostly about poverty alleviation by using a small credit project. Srivastava (2005) stated about poverty alleviation and reinforcement of community power by using microcredit. Yunus whom founded the Krameen Bank in 1974 found that women in a village producing bamboo chairs got a loan for purchasing raw materials could alleviate their poverty and be self-reliant. An opportunity in the assessment of capital sources helped them form self-help groups. There is an agreement whether microcredit is beneficial or not. It is found that microcredit can be an emergency source of loan. (Vonderlack-Navarro \& Sherraden, 2007). However, it is found that microcredit is a strategy which helps sustainable community development (Woodworth \& Hiatt, 2003). Besides, the promotion of women roles in coordination and collaboration in the society in successfully had done. (Drolet, 2009). 


\section{Ml Macrothink}

Environmental Management and Sustainable Development

ISSN 2164-7682

2014, Vol. 3, No. 1

For the community finance study in Thailand, Coleman (2006) suggested that it should focus on the poor as a target group. Huerta (2010) found that the level of debts of the village fund had a negative relationship with loan payment. Late debt payment would result in social punishment in terms of trustworthiness. Shigetomi (2011) found that the community financial organizations in Thailand aroused form supporting management agencies but all operations are roles of leaders and community members.

It can be concluded that microcredit groups help support the society based on social safety net. In 2005, the Union Nation Organization claimed the international Year of Microcredit: IYM which aimed to encourage the small credit to alleviate poverty. Besides, the microfinance was a main topic in the convention on the Millennium Development Goals relating to sustainable development (Srivastava, 2005).

\section{Research Methodology}

Field trip survey was conducted in Northeast Thailand for finding secondary data through printed material. Primary data were obtained from in-depth interviewing with community leaders, SPGs sampling are presidents and members of saving groups: Baan Kam PSG, Moo 2, Baan Kham sub-district, Jaturat district, Chaiyaphum province; Baan Jod PSG, Moo 16, Chao Tha sub-district, Kamalasai district, Kalasin province; Baan Thabsawai, Moo 1, Thabsawai district, Huay Thalaeng district, Nakhon Ratchasima province; and Baan Nonghin PSG, Moo 5, Khamhaiyai sub-district, Don Moddaeng district, Ubon Ratchathani province. This study employed non-participatory observation and tape recording and obtained data were analyzed for finding answers of objective of the study.

\section{Analyses and Result Discussion}

Results of data analyses can be concluded as follows:

\subsection{Saving for Production Groups Management}

Forming of saving groups is encouraging local people to have a sense of belonging and responsibility in effective group operation. Thus, PSG is a mechanism driving community economy and leading to the coordination between government and private sectors. This aims to solve problems in lack of capital and loan shark. Generally, there is registration, account, and preparation of rules or regulations for the benefits of group members. Besides, there is the operation on financial statement preparation and audit, profit sharing, responsibility of committee, and management on rules and regulations of the groups.

\subsection{Effectiveness of Sustainable Development of the Saving for Production Groups}

SPGs arise from factors on leader and committee and the principle of managerial administration as well as sufficiency economy result in the success of SPGs. Besides, it can solve community problems by using folk wisdoms due to the development of human capital. Unity and rules or regulations of the group help strengthen the saving group for self-reliance.

\subsubsection{Effectiveness of Learning Promotion through Social and Economic Activities}

Luxchaigul (2013) had conducted a study on a guideline for learning promotion to enriching 
the effectiveness of economic activities of the saving group for production. He suggested that the economic activities should promote the following: saving integrity, spending money in accordance with the objectives, supplementary incomes, training, welfare, and sufficiency economy. For economic activity learning, it should be consistent with needs of local people and sufficiency economy. Beside, effective use of local media and learning from external community should be focused. Regarding, learning for increased effectiveness, it should have career promotion planning as we well as an increase in committee potential. Also, group members must be motivated to perceive the benefits of mutual learning on the five aspects of virtue of the saving group. For factors effecting learning for increased effectiveness, appropriate learning atmosphere should be facilitated as well as the importance of cultural condition, local historical background, local wisdoms, and principle of sufficiency economy, environmental conservation, and natural resources of the community. Besides, the following should be done: amendment of rules and regulations, financial discipline, sufficiency economy adoption, household account, vegetable garden, and external support on knowledge, materials, equipment, and technology.

\subsubsection{Effectiveness of the Networking Activity Development for Self-reliance and} Socioeconomic Strengthening.

SPGs have effectiveness on economic activities data moderate level in terms of saving for production and social welfare rather than career promotion. This implies that the saving group places the importance on the operation of saving for production. Group members are provided welfares for a better livelihood, e.g. the promotion of chicken domestication, fishing culture, and vegetable growing.

Regarding the consideration of effectiveness group, the low effectiveness group should place the importance on the activities of saving for production rather than the provision of welfares and saving for production. The high effectiveness group should place the importance on career promotion rather than saving for production. Besides, all of the effectiveness groups should have career promotion. As a matter of fact, the effectiveness of economic activities arises from the philosophy of sufficiency economy. Learning within the group is important for knowledge enhancement. The effectiveness arises from this learning can develop potential of people in the community and the saving group.

\section{Conclusions}

\subsection{Conclusions}

An increase in the effectiveness of sustainable development by enriching skills, knowledge about social and economic aspects which is consistent with individual potential, local tradition, and local wisdoms needs to be dependent on lifelong learning. For the management of SPGs, it is mostly the application of the principle of sufficiency economy for development. This will had to self-reliance and negotiation power on social, economic, and political aspects. It can be seen that the guideline for human capital development focuses on human-centered but it lacks of continual support by people in the community. This includes the advantage in competition, advancement in management, and future network activities 


\section{Macrothink

development.

\subsection{Suggestions}

\subsubsection{Policy Suggestions}

An increase in the effectiveness of development of SPGs is the role of group leaders, committee, members, and supporting government and private agencies. They must find a method for development to create intellectual method for human capital through human capital development for effective management of the saving group. Therefore, supporting agencies should determine integrated strategic plan leading to practice. A guideline for development should focus on man centered for the advantage in future competition.

\subsubsection{Recommendations}

This study focuses on the effectiveness of sustainable development of SPGs. This can be done by the promotion of learning though the operation of economic activities with different effectiveness. Therefore, further study should analyzed and examine whether which form of learning promotion is appropriate and has a highest effectiveness for sustainable development.

\section{Acknowledgement}

This Research has courtesy facilitated from Bureau of Community Capital and Financial Organization Development of The Community Development Department, Community Development Provincial Office, The committee and member of Saving for Production Groups (SPGs) in Northeast and also supported from staff and friend from Chulalongkorn University. On this occasion, the author is very grateful to this kindness.

\section{References}

Bureau of Community Capital and Financial Organization Development. (2010). Knowledge: Management of Saving for Production Groups (For Staff). Bangkok: The Community Development Department.

Chotechuang, Pridi. (2001). Saving for Production Groups: Process of Saving Capital by Community. Community Development Journal, 40(2), 25-31.

Coleman, Brett E. (2002). Microfinance in Northeast Thailand: Who benefit and hoe much? Economic and Research Department Asian Development Bank.

Dhammapidok. (2006). Sustainable Development. Bangkok: Kamol.

Draf, Richard L. (1998) Organization Theory and Design. Ohio: South-Western College Publishing.

Drolet, Julie. (2009). Women and Microcredit: Implications for social and economic development. Social Development Issues, 31(1), 55-68.

Holmberg, Johan ed. (1992), Making Development Sustainable: Redefining Institutions, Policy, and Economics. Washington, D.C.: Island Press. 


\section{Macrothink}

Environmental Management and Sustainable Development

ISSN 2164-7682 2014, Vol. 3, No. 1

Huerta, de la Adriana. (2010). Microfinance in rural and urban Thailand : policies, social ties and successful performance. Master Thesis, University of Chicago. USA.

Insawaang, Padet. (2000). The Best of Saving for Production Groups. Division of Social Economy and Environment, Community Development Department. Bangkok: CDD.

Kongkasawat, Thamrongsak. (2007). Human Capital: Indicators Specify for Development. Bangkok: Technology Promotion Association (Thailand-Japan).

Luxchaigul, Nat. (2013). Learning Enhancement Guidelines to Increase the Effectiveness of Economic Activities of Saving for Production Groups. Doctoral thesis of Development Education major, Chulalongkorn University, Thailand.

PuangNgaam, Kowit. (2010). Community and Local Self Governance. Bangkok: Borpitt Printing Limited.

Srivastava, Paritosh. (2005). Reducing Poverty and Empowering Communities. UN Chronicle, 42(3), 45-46.

Parliamentary Commissioner for the Environment. (2004). See Change: Learning and Education for Sustainability. New Zealand Government: Wellington.

Tangmelap, Padet and Nuanlaor, Damrong. (2001). Concluding Matter for self-development and Community. Bangkok: Central Media.

Shigetomi, Shinichi. (2011). Organizational capability of local societies in rural development. Social Development Issues, 33(1), 24-34.

SomIn, Apisak. (1982). Northeast Geography. Bangkok: Ponsak and Associate.

Therasatwat, Suwit. (2003). History of Economic Community in Northeast 1945 - 2001. Bangkok: SangSan.

UNESCO. (2010) Teaching and Learning for a Sustainable Future. [online]:Available: http://en.unesco.org/ (January 7, 2014)

Vonderlack-Navarro, Rebecca and Sherraden, M. S. (2007). Social Development Issues, 29(1), 65-80.

Walaisathira, Parichart. (2005). New Paradigms with Learning Community. Bangkok: SCB Foundation.

Woodworth, Warner and Hiatt, Shon. (2003). Socio-Economic Results of Microfinance in Mexico and Ecuador. J Utah Academic Science Lett, 80, 57-66.

\section{Copyright Disclaimer}

Copyright reserved by the author(s).

This article is an open-access article distributed under the terms and conditions of the Creative Commons Attribution license (http://creativecommons.org/licenses/by/3.0/). 